\title{
Delayed diagnosis of adrenal insufficiency in a patient with severe penoscrotal hypospadias due to two novel P450 side-change cleavage enzyme (CYP1 1A 1) mutations (p.R360W; p.R405X)
}

\author{
Silvia Parajes, Angel OK Chan ${ }^{1}$, W M But ${ }^{2}$, Ian T Rose, Angela E Taylor, Vivek Dhir, Wiebke Arlt and Nils Krone \\ School of Clinical and Experimental Medicine, Institute of Biomedical Research, Centre for Endocrinology, Diabetes and Metabolism, University of \\ Birmingham, Wolfson Drive, Birmingham B15 2TT, UK and Departments of ${ }^{1}$ Pathology and ${ }^{2}$ Paediatrics, Queen Elizabeth Hospital, Hong Kong, People's \\ Republic of China \\ (Correspondence should be addressed to N Krone; Email: n.p.krone@bham.ac.uk)
}

\begin{abstract}
Context: Cytochrome P450 side-chain cleavage enzyme (CYP11A1) catalyses the first and rate-limiting step of steroidogenesis, the conversion of cholesterol to pregnenolone. CYP11A1 deficiency is commonly associated with adrenal insufficiency, and in 46,XY individuals, with variable degrees of disorder of sex development (DSD).

Patient and methods: The patient was born with hyperpigmentation, micropenis, penoscrotal hypospadias, and mild cryptorchidism. Biochemical and hormonal findings were normal except for low testosterone and low-borderline cortisol. However, no short synacthen test was undertaken. Development was unremarkable apart from an episode labeled as sepsis with documented hyperkalemia and elevated C-reactive protein at age 15 days. Diagnosis of 46,XY DSD was made at age 2.5 months. Progression of hyperpigmentation prompted further investigations and the diagnosis of adrenal insufficiency was established at 2 years with raised ACTH, normal renin activity, and failure of cortisol to respond to short synacthen test. Genetic analyses were performed. The novel CYP11A1 mutations were characterized in vitro and in silico.

Results: The patient was compound heterozygous for two novel CYP11A1 mutations, p.R360W and p.R405X. p.R360W retained 30-40\% of wild-type activity. In silico analyses confirmed these findings and indicated that p.R $405 \mathrm{X}$ is severe.

Conclusions: This study demonstrates the pathogenicity of two novel CYP11A1 mutations found in a patient with delayed diagnosis of CYP11A1 deficiency. Patients with partial deficiencies of steroidogenic enzymes are at risk to be misdiagnosed if adrenal function is not assessed. The adrenocortical function should be routinely assessed in all patients with DSD including severe hypospadias of unknown origin to prevent life-threatening adrenal crises.
\end{abstract}

European Journal of Endocrinology 167 881-885

\section{Introduction}

The activity of Cytochrome P450 side-chain cleavage enzyme (CYP11A1, EC 1.14.15.6) is the prerequisite for all mineralocorticoid, glucocorticoid, and sex steroid biosynthesis as it catalyzes its first step, the conversion of cholesterol to pregnenolone (1). It is encoded by the CYP11A1 gene, localized on the long arm of chromosome 15 (15q23-q24). CYP11A1 synthesizes pregnenolone from cholesterol in three consecutive catalytic steps: 20 $\alpha$-hydroxylation, 22R-hydroxylation, and cleavage of the $\mathrm{C} 20-\mathrm{C} 22$ carbon side chain of cholesterol (1).

Only 11 patients with CYP11A1 deficiency (OMIM \#118485) have been reported so far. The clinical phenotype is similar to congenital lipoid adrenal hyperplasia (CLAH; OMIM \#201710) that is caused by deficient mitochondrial cholesterol import due to mutations in the steroidogenic acute regulatory protein (STAR) (2). Severe CYP11A1 deficiency manifests with female external genitalia irrespective of chromosomal sex and with early onset adrenal insufficiency, usually manifesting within the first hours or days of life $(3,4)$. A milder form of CYP11A1 deficiency has also been described, associated with delayed onset of adrenal insufficiency and variable degrees of 46,XY disorder of sex development (DSD) $(5,6,7,8,9)$ or also normal male genital development (10). Adrenal glands are normal size or absent in CYP11A1 deficiency $(10,11)$, in contrast to CLAH (2, 12, 13, 14). In vitro expression studies assessing the residual activity of mutant CYP11A1 suggest that, overall, the genotype correlates well with the degree and onset of adrenal insufficiency (10). 
Herein, we report a case of delayed diagnosis of adrenal insufficiency in a patient manifesting at birth with severe penoscrotal hypospadias and inadequate adrenal steroidogenesis caused by two novel CYP11A1 mutations. Our data highlights the importance of considering adrenal insufficiency in the differential diagnosis of 46,XY DSD patients. Adrenal function should be assessed in cases with suspicion of adrenal insufficiency to prevent life-threatening adrenal crises.

\section{Patient, materials, and methods}

\section{Case report}

The patient was born at term to non-consanguineous parents of Chinese origin. At 12-week gestation, an episode of threatened miscarriage occurred and the mother was treated with progesterone injections. At birth, the child presented with micropenis $(1 \times 0.6 \mathrm{~cm})$, penoscrotal hypospadias, chordee, and mild cryptorchidism; in addition, generalized hyperpigmentation was noted. Further investigations revealed a 46,XY karyotype.

On day 2, serum testosterone was normal (3.6 nmol/l; normal reference range (NR), 3.0-12.0) and dropped to $1.7 \mathrm{nmol} / \mathrm{l}$ on day 9 . On day 9 , plasma ACTH and 17-hydroxyprogesterone (17OHP) concentrations were normal (Table 1). Baseline cortisol was low $(52 \mathrm{nmol} / \mathrm{l}$ on a random afternoon sample; normal, NR: 64-327) and increased to $455 \mathrm{nmol} / \mathrm{l}$ during a urinary tract infection (UTI) at 2 weeks of age that was associated with increased C-reactive protein $(55.7 \mathrm{mg} / \mathrm{l}$; normal, <5) and hyperkalemia $(6.9 \mathrm{mmol} / \mathrm{l}$; normal, 3.5-5.1) with mildly decreased sodium $(132 \mathrm{mmol} / \mathrm{l}$; normal, 136-145) and normal plasma glucose $(74 \mathrm{mg} / \mathrm{dl})$. Electrolytes were within normal range after the UTI episode and on follow-up measurements at 4 and 7 months of age.

At 2.5 months, a human chorionic gonadotropin stimulation test confirmed gonadal dysfunction with insufficient response of androstenedione $(<0.4 \mathrm{nmol} / \mathrm{l})$ and testosterone $(0.7 \mathrm{nmol} / \mathrm{l})$. At this time, cortisol

Table 1 Hormonal and biochemical findings at birth and at the time of diagnosis before treatment initiation.

\begin{tabular}{lccc}
\hline & & \multicolumn{2}{c}{ At 2 years } \\
\cline { 4 - 4 } & $\begin{array}{c}\text { At birth } \\
\text { (day 9; NR) }\end{array}$ & Basal (NR) & Stimulated \\
\hline ACTH (pmol/l) & $6.5(<10.1)$ & $565(<10.1)$ & \\
Cortisol (nmol/l) & $52(67-327)$ & $54(138-635)$ & 64 \\
Progesterone (nmol/l) & $5.9(0.7-4.3)$ & $<0.1(0.2-1.7)$ & \\
17OHP (nmol/l) & $1.5(0.5-20)$ & $0.9(<3)$ & 0.9 \\
Plasma renin activity & & $8.34(1.7-11.2)$ & \\
$\quad(\mathrm{ng} / \mathrm{ml}$ per h) & & & \\
Aldosterone (pmol/l) & $3479(190-5100)$ & $223(140-2220)$ & \\
Testosterone (nmol/l) & $1.7(3.0-12)$ & $<0.4(0.1-0.5)$ & \\
LH (IU/l) & $2.3(1.7-8.6)$ & $7.3(<1.3)$ \\
FSH (IU/l) & $7.5(1.5-12.4)$ & $27.3(0.2-2.8)$ & \\
\hline
\end{tabular}

NR, normal reference range; 17OHP, 17-hydroxyprogesterone. concentration on a random blood sample was normal (193 nmol/l on a random morning sample; NR: 138-635) but neither basal ACTH was measured nor a short synacthen test was performed. Ultrasound demonstrated the right testis low in the inguinal canal and the left testis within the scrotum. Small echogenic foci in the ultrasound were suggestive of testicular microlithiases. Adrenal glands were of normal size and appearance. Diagnosis of 46,XY DSD was made based on these clinical and biochemical findings.

Penile length increased to $2.2 \mathrm{~cm}$ after initiation on i.m. injections of testosterone $(25 \mathrm{mg})$ every 4 weeks over a period of 3 months from the age of 10 months. Uneventful bilateral orchidopexy was performed at the age of 15 months.

At the age of 2 years, a progression of the generalized hyperpigmentation was noted, now with involvement of the mucosa. The patient was referred to a pediatric endocrinologist and adrenal insufficiency was suspected. ACTH levels were elevated (565 pmol/l; normal, <10.1). A short synacthen test revealed low basal and stimulated cortisol, 17OHP, and progesterone concentrations (Table 1). There was no clinical evidence of salt loss. Aldosterone, plasma renin activity, and electrolytes (sodium, $139 \mathrm{mmol} / \mathrm{l}$; NR: $136-145 \mathrm{mmol} / \mathrm{l}$; potassium, $4.6 \mathrm{mmol} / \mathrm{l}$; NR: $3.5-5.7 \mathrm{mmol} / \mathrm{l})$ were within the normal range (Table 1). The patient was commenced on hydrocortisone replacement. Six months later, aldosterone concentrations dropped to $127 \mathrm{pmol} / \mathrm{l}$ (NR: 140-2220) with mid normal plasma renin activity $(6.7 \mathrm{ng} / \mathrm{ml}$ per h; NR: 1.7-11.2) and fludrocortisone treatment was initiated.

\section{DNA analysis}

Molecular genetic analysis of the coding sequence and exon-intron boundaries of the SF1, STAR, and CYP11A1 genes was performed after obtaining informed consent from the parents and approved by the Local Ethics Committee. Exons 6 and 7 of the CYP11A1 gene were PCR amplified and sequenced in the parents for segregation analysis. DNA was extracted from peripheral blood leukocytes following standard procedures. Sequence variants were designated according to Human Genome Variation Society recommendations (www.hgvs.org/rec.html) using the following reference sequences: GenBank, NG_007973 (gDNA); GenBank, NM_000781.2 (cDNA); and GenBank, NP_000772.2 (protein). The location of the first nucleotide used for gDNA and cDNA numbering is the A of the ATG translation initiation codon of the reference sequence.

\section{In vitro characterization of mutant CYP11A1 activity}

The in vitro analysis of the p.R $360 \mathrm{~W}$ mutation was performed as described previously (10). In brief, the p.R360W mutation was recreated in the pcDNA6-CYP11A1 vector by site-directed mutagenesis 
following a standard protocol (QuickChange XL Site-Directed Mutagenesis Kit, Stratagene, Amsterdam, The Netherlands). The pcDNA6-CYP11A1 vector contains the coding DNA sequence of wild-type CYP11A1 with a 14 amino acids sequence tag (V5-tag, GKPIPNPLLGLDST) at the 3 '-terminus.

CYP11A1 enzyme activity was assessed by measuring the conversion of cholesterol and 22R-hydroxycholesterol, respectively, into pregnenolone. 22R-hydroxycholesterol is an intermediate product not relying on STAR-mediated transport to enter the mitochondria. Thereby, it allowed measuring CYP11A1 activity STAR-independent. COS7 cells were transiently co-transfected with $1 \mu \mathrm{g}$ wildtype or mutant pcDNA6-CYP11A1, $0.5 \mu \mathrm{g}$ wild-type STAR cDNA (pcDNA6-STAR), and $0.5 \mu \mathrm{g}$ bovine adrenodoxin cDNA (pBAdx4, kindly provided by Prof. M R Waterman, Department of Biochemistry, Vanderbilt University School of Medicine, Nashville, Tennessee). STAR was not overexpressed for the activity assay measuring the conversion of 22R-hydroxycholesterol to pregnenolone. pcDNA6/V5-HisB empty vector was used as a negative control.

Forty-eight hours after transfection, cells were incubated with either $2.5 \mu \mathrm{mol} / \mathrm{l}$ cholesterol or $2 \mu \mathrm{mol} / \mathrm{l} 22 \mathrm{R}$-hydroxycholesterol for 24 or $4 \mathrm{~h}$ respectively. Conversion of these substrates into pregnenolone was measured by liquid chromatography/tandem mass spectrometry. Mutant CYP11A1 activity was expressed as a percentage of substrate conversion in micromoles per milligram of total protein per minute, defining wildtype activity as $100 \%$. Assays were performed in at least three independent triplicate experiments, and data are presented as mean \pm s.e.M. using the GraphPad Prism Software version 5.0 (GraphPad, Inc., San Diego, CA, USA). Western blot analysis was performed using $8 \mu \mathrm{g}$ of total protein and $1 \mu \mathrm{g} / \mathrm{ml}$ anti-V 5 mouse antibody.

\section{In silico analysis of the novel CYP11A1 mutations}

The crystal structure of human CYP11A1 (http://www. rcsb.org/pdb, PDB code 3NA0) was used to analyze the impact of the p.R360W and p.R405X mutations on the three-dimensional structure of the CYP11A1 enzyme using the Molsoft ICM Browser Pro Software (Molsoft L.L.C, La Jolla, CA, USA).

\section{Results}

As a first step, based on the incidence of mutations in SF 1 or STAR associated with AI and 46,XY DSD, the mutation analysis of the SF1 and STAR genes was performed. No disease-causing mutations were found in either of these candidate genes. The CYP11A1 mutation analysis was performed as the next diagnostic procedure. Two novel CYP11A1 mutations were
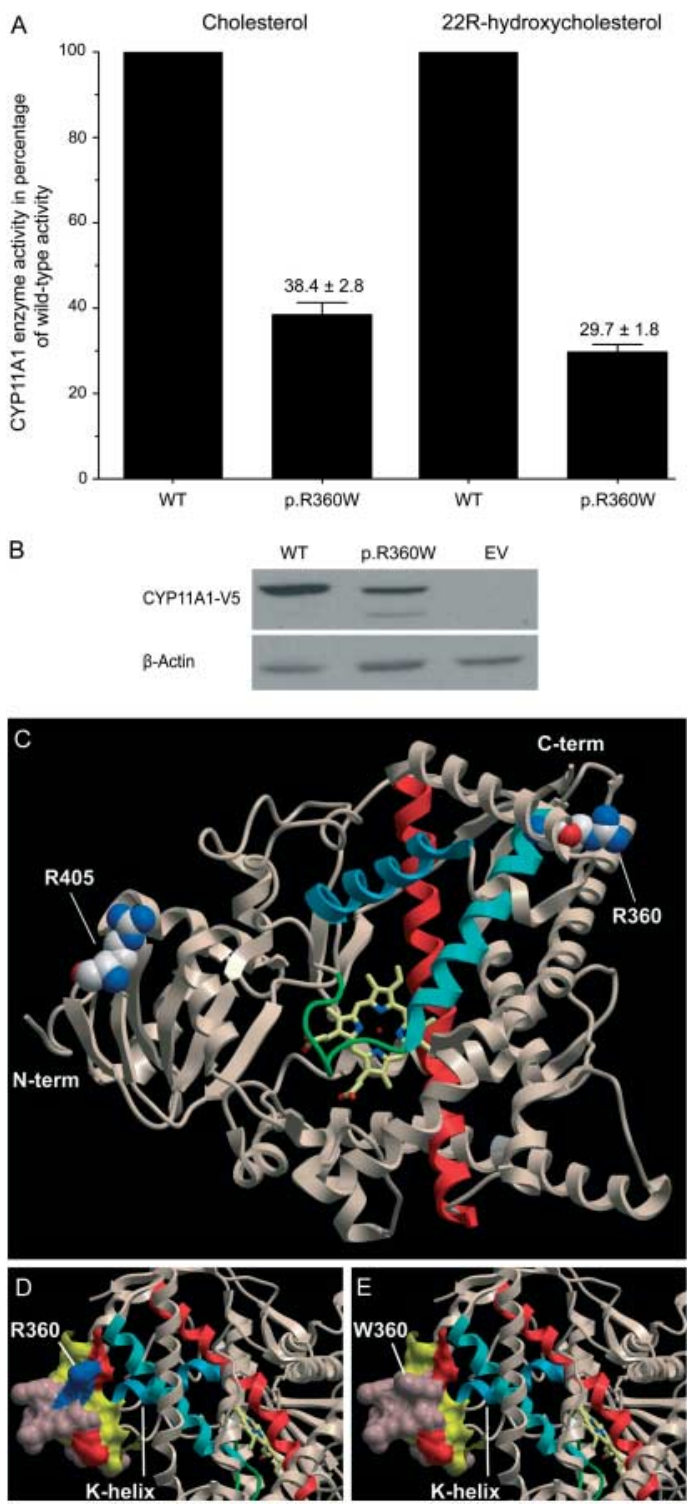

Figure 1 In vitro and in silico analysis of the two novel CYP11A1 mutations. (A) CYP11A1 residual enzyme activity obtained for the conversion of cholesterol and 22R-hydroxycholesterol at a substrate concentration of 2.5 and $2 \mu \mathrm{mol} / \mathrm{l}$. Residual enzyme activity is expressed as percentage of wild-type (WT) activity, which is defined as $100 \%$. Assays were performed in triplicate in three independent experiments. Error bars indicate mean \pm S.E.M. (\%). (B) Representative western blot using anti-V5 antibody to detect expression of wild-type (WT) and mutant CYP11A1 tagged with V5 at the C-terminus and the pcDNA6/V5-HisB empty vector (EV). An anti$\beta$-actin antibody was used to assure equivalent protein load for WT, mutant, and EV. (C, D and E) Three-dimensional molecular model of CYP11A1. (C) Localization of the two novel CYP11A1 mutations on the crystal structure of human CYP11A1 (http://www.rcsb.org/ $\mathrm{pdb}$, PDB code 3NA0). (D) Localization of the $\mathrm{R} 360$ residue and polarity of the protein surface when an arginine is present at this position. (E) Polarity change on the protein surface induced by a tryptophan at residue 360. N-term, amino terminus; C-term, carboxy terminus. The I-helix is colored in red, the L-helix in light blue, the $\mathrm{K}$-helix in dark blue, and the cysteine pocket in green. The structural representations were generated using Molsoft ICM Browser Pro. 
found: a cytosine to thymine transition at nucleotide position 27921 (c.1078C $>$ T, p.R360W) on the maternal allele and a cytosine to thymine transition at nucleotide position 28327 (c.1213C > T, p.R405X) on the paternal allele.

The p.R360W mutation retained 38 and $30 \%$ of wild-type CYP11A1 in vitro activity for the conversion of cholesterol and 22R-hydroxycholesterol to pregnenolone respectively (Fig. 1A). Western blot analyses consistently showed lower protein levels for the p.R360W mutation than for the wild-type, suggesting that p.R360W may impair protein stability, also indicated by consistent evidence of protein degradation in the mutant protein blots (Fig. 1B).

The arginine residue at position 360 of the CYP11A1 protein is highly conserved across species, but not across mitochondrial cytochrome P450 (CYP) type I enzymes (Fig. 2). This residue is localized at the amino-terminus of the J-helix. Substitution of a positivecharged arginine by an aliphatic nonpolar tryptophan

\begin{tabular}{|c|c|c|}
\hline A & $\vec{\nabla} \boldsymbol{\nabla}$ & \\
\hline human & NLKVQDMLRAEVLAARHQAQGDMATMLQLVP & 375 \\
\hline cow & SLNVQEMLREEVLNARRQAEGDISKMLQMVP & 374 \\
\hline sheep & SLNVQEMLRKEVLNARRQAEGDISKMLQMVP & 374 \\
\hline wild pig & SLNVQEMLREEVLNARRQAQGDTSKMLQLVP & 374 \\
\hline horse & NLRVQEMLREEVLAARRQAQGDTSTMVQMVP & 374 \\
\hline mouse & NLKVQEMLRAEVLAARRQAQGDMAKMVQLVP & 371 \\
\hline rat & NLKVQEMLRAEVLAARRQAQGDMAKMVQLVP & 372 \\
\hline zebrafish & QPDLQDELRAEISAARIAFKGDMVQMVKMIP & 368 \\
\hline chicken & SPGIQERLRAEVLAAKQEAQGDRVKMLKSIR & 367 \\
\hline & $\stackrel{405}{\nabla}$ & \\
\hline human & ISVTLQRYLVNDLVLRDYMI PAKTLVQVAIY & 420 \\
\hline cow & ISVTLQRYPESDLVLQDYLI PAKTLVQVAIY & 419 \\
\hline sheep & ISVTLQRYPESDLVLQDYLI PAKTLVQVAIY & 419 \\
\hline wild pig & ISVTLQRYLVNDLVLRDYMI PAKTLVQVAVY & 419 \\
\hline horse & IAVTLQRYPQNDLVIRDYMI PAKTLVQVSIY & 419 \\
\hline mouse & ISVTLQRYTVNDLVLRNYKI PAKTLVQVASF & 417 \\
\hline rat & ISVTLQRYIVNDLVLRNYKI PAKTLVQVASY & 417 \\
\hline zebrafish & VAMSLPRE ITEDTVIQNYHIPAGTLVQLGVY & 413 \\
\hline chicken & VAVTLQRYTTQEVILQDYRI PPKTLVQVGLY & 412 \\
\hline B & 360 & \\
\hline CYP11A1 & NLKVQDMLRAEVLAARHQAQGDM--ATMLQL & 418 \\
\hline CYP24A1 & NPQVQQKLLKEIQSVLPENQVPR--AEDLRN & 418 \\
\hline CYP27B1 & HPEVQTALHSEITAALSPGSSAYPSATVLSQ & 369 \\
\hline CYP11B1 & NPNVQQALRQESLAAAAS ISEHP--QKATTE & 364 \\
\hline CYP11B2 & NPDVQQILRQESLAAAAS ISEHP--QKATTE & 364 \\
\hline & & \\
\hline CYP11A1 & ISVTLQRYLVNDLVLRDYMI PAKTLVQVAIY & 420 \\
\hline CYP24A1 & SVPFTTRTLDKATVLGEYALPKGTVLMLNTQ & 420 \\
\hline CYP27B1 & VVPGNSRVPDKDIHVGDY I I PKNTLVTLCHY & 413 \\
\hline CYP11B1 & VGLFLERVASSDLVLQNYHI PAGTLVRVFLY & 408 \\
\hline CYP11B2 & VGLFLERVVSSDLVLQNYHIPAGTLVQVFLY & 408 \\
\hline
\end{tabular}

Figure 2 ClustalW alignment of the two novel CYP11A1 mutations found in a patient with mild CYP11A1 deficiency. (A) Alignment of human CYP11A1 with ortholog proteins from another species. (B) Alignment of hCYP11A1 with other human mitochondrial cytochrome P450 type I enzymes. The R360 and R405 are shaded and marked by a triangle. results in a polarity change on the protein surface, but otherwise no major structural changes were apparent (Fig. 1C, D and E).

The arginine at codon 405 is not well conserved (Fig. 2) and localizes to the $\mathrm{C}$-terminal part of the loop between the $\beta 2-1$ and $\beta 2-2$ sheets (Fig. 1C). A premature truncation of the protein at this position eliminates protein domains crucial for CYP11A1 activity (15). Therefore, the novel nonsense p.R405X mutation is predicted to result in a complete loss of CYP11A1 function.

\section{Discussion}

Herein, we present a case of delayed diagnosis of adrenal insufficiency in a patient with penoscrotal hypospadias caused by two novel CYP11A1 mutations, p.R360W and p.R405X. In vitro and in silico analyses were consistent with the clinical findings and confirmed the diagnosis of CYP11A1 deficiency in the patient. This report demonstrates that diagnosis of CYP11A1 deficiency can be challenging and highlights the importance of adrenal function assessment to provide adequate clinical diagnosis and to prevent life-threatening adrenal crises.

Partially CYP11A1 inactivating mutations are usually associated with onset of adrenal insufficiency between the age of 2 and 9 years $(7,8,9,10)$. Earlier onset of adrenal symptoms has been reported in a patient compound heterozygote for the mild p.L141W and the severe p.V415E mutations (4). Signs and symptoms suggest that adrenal steroidogenesis was already partially impaired in our patient soon after birth, with generalized hyperpigmentation, low cortisol levels, and insufficient cortisol response during a UTI sepsis episode. Furthermore, it is tempting to speculate that the episode of premature labor at 12 weeks of gestation may be due to insufficient placental CYP11A1 activity (16).

Our current data together with previous findings (4) suggest that compound heterozygosity for a mild and a severe mutation may advance onset of signs and symptoms of impaired adrenal function in patients with mild CYP11A1 deficiency. The diagnosis of adrenal insufficiency can be missed by normal baseline cortisol concentrations and lack of adequate adrenal function assessment. Similarly, to our previous report of two siblings with partial CYP11A1 deficiency (10), our patient had normal plasma renin activity at the age of 2 years when not stressed. Mild CYP11A1 deficiency can be thereby misdiagnosed as familial glucocorticoid deficiency in 46,XX patients and 46,XY patients with no or very mild DSD and apparently normal mineralocorticoid activity.

Prenatally, partial impairment of pregnenolone synthesis is associated with a broad phenotypic spectrum with regard to genital presentation (11) and postnatally with gonadal insufficiency $(7,4,10)$. Similarly to other inborn errors of steroidogenesis such as CLAH (13) and HSD3B2 deficiency (17), the 
CYP11A1 genotype correlates poorly with the phenotype of the external genitalia. CYP11A1 mutations with residual enzyme activities similar to p.R360W were associated with either normal female external genitalia in $46, X Y$ patients (p.L141W and p.A359V) $(4,7)$ or normal male genital development (p.R451W) (10). The moderate degree of 46,XY DSD in our patient indicates that gonadal steroidogenesis was only partly impaired during early development. However, increased gonadotropin levels at age 2 years suggest progressive loss of Leydig cell function. The reassessment of gonadal function at early puberty and clinical follow-up will be essential to assess the requirements for sex hormone replacement during puberty and the potential for fertility in our patient.

We describe two novel CYP11A1 mutations, p.R360W and p.R405X, associated with early onset and mild adrenal insufficiency and moderate 46,XY DSD. Our data demonstrate the partially inactivating nature of the novel p.R360W mutation. Importantly, this report exemplifies the importance to properly assess adrenal function at the time of first clinical presentation to ensure timely diagnosis of patients with mild inborn and possibly progressively developing adrenal insufficiency. Adrenal insufficiency must be considered in the differential diagnosis of patients presenting with 46,XY DSD including severe hypospadias to establish an early correct diagnosis and to prevent potential life-threatening adrenal crises.

\section{Declaration of interest}

The authors declare that there is no conflict of interest that could be perceived as prejudicing the impartiality of the research reported.

\section{Funding}

This study was supported by a Marie Curie Intra-European fellowship (grant no. IEF-GA-2009-255424 to S Parajes), the Medical Research Council UK (program grant no. 0900567 to W Arlt), and the Wellcome Trust (Clinician Scientist Fellowship GR079865MA to N Krone).

\section{References}

1 Miller WL \& Auchus RJ. The molecular biology, biochemistry, and physiology of human steroidogenesis and its disorders. Endocrine Reviews 201132 81-151. (doi:10.1210/er.2010-0013)

2 Bose HS, Sugawara T, Strauss JF \& Miller WL. The pathophysiology and genetics of congenital lipoid adrenal hyperplasia. New England Journal of Medicine 1996335 1870-1878. (doi:10.1056/ NEJM199612193352503)

3 Hiort O, Holterhus P-M, Werner R, Marschke C, Hoppe U, Partsch C-J, Riepe FG, Achermann JC \& Struve D. Homozygous disruption of $\mathrm{P} 450$ side-chain cleavage (CYP11A1) is associated with prematurity, complete $46, \mathrm{XY}$ sex reversal, and severe adrenal failure. Journal of Clinical Endocrinology and Metabolism 200590 538-541. (doi:10.1210/jc.2004-1059)

4 Kim CJ, Lin L, Huang N, Quigley CA, AvRuskin TW, Achermann JC \& Miller WL. Severe combined adrenal and gonadal deficiency caused by novel mutations in the cholesterol side chain cleavage enzyme, P450scc. Journal of Clinical Endocrinology and Metabolism 200893 696-702. (doi:10.1210/jc.2007-2330)
5 Tajima T, Fujieda K, Kouda N, Nakae J \& Miller WL. Heterozygous mutation in the cholesterol side chain cleavage enzyme (P450scc) gene in a patient with 46, XY sex reversal and adrenal insufficiency. Journal of Clinical Endocrinology and Metabolism 200186 3820-3825. (doi:10.1210/jc.86.8.3820)

6 Katsumata N, Ohtake M, Hojo T, Ogawa E, Hara T, Sato N \& Tanaka T. Compound heterozygous mutations in the cholesterol side-chain cleavage enzyme gene (CYP11A) cause congenital adrenal insufficiency in humans. Journal of Clinical Endocrinology and Metabolism 200287 3808-3813. (doi:10.1210/jc.87.8.3808)

7 Kandari al H, Katsumata N, Alexander S \& Rasoul MA. Homozygous mutation of P450 side-chain cleavage enzyme gene (CYP11A1) in 46, XY patient with adrenal insufficiency, complete sex reversal, and agenesis of corpus callosum. Journal of Clinical Endocrinology and Metabolism $2006 \mathbf{9 1} 2821-2826$. (doi:10.1210/jc.2005-2230)

8 Rubtsov P, Karmanov M, Sverdlova P, Spirin P \& Tiulpakov A. A novel homozygous mutation in CYP11A1 gene is associated with lateonset adrenal insufficiency and hypospadias in a 46, XY patient. Journal of Clinical Endocrinology and Metabolism 2009 94 936-939. (doi:10.1210/jc.2008-1118)

9 Sahakitrungruang T, Tee MK, Blackett PR \& Miller WL. Partial defect in the cholesterol side-chain cleavage enzyme P450scc (CYP11A1) resembling nonclassic congenital lipoid adrenal hyperplasia. Journal of Clinical Endocrinology and Metabolism 201196 792-798. (doi:10.1210/jc.2010-1828)

10 Parajes S, Kamrath C, Rose IT, Taylor AE, Mooij CF, Dhir V, Grötzinger J, Arlt W \& Krone N. A novel entity of clinically isolated adrenal insufficiency caused by a partially inactivating mutation of the gene encoding for P450 side-chain cleavage enzyme (CYP11A1). Journal of Clinical Endocrinology and Metabolism 201196 E1798-E1806. (doi:10.1210/jc.2011-1277)

11 Hauffa B \& Hiort O. P450 side-chain cleavage deficiency - a rare cause of congenital adrenal hyperplasia. Endocrine Development 201120 54-62. (doi:10.1159/000321215)

12 Metherell LA, Naville D, Halaby G, Begeot M, Huebner A, Nurnberg G, Nurnberg P, Green J, Tomlinson JW, Krone NP, Lin L, Racine M, Berney DM, Achermann JC, Arlt W \& Clark AJL. Nonclassic lipoid congenital adrenal hyperplasia masquerading as familial glucocorticoid deficiency. Journal of Clinical Endocrinology and Metabolism 2009 94 3865-3871. (doi:10.1210/jc.2009-0467)

13 Sahakitrungruang T, Soccio RE, Lang-Muritano M, Walker JM, Achermann JC \& Miller WL. Clinical, genetic, and functional characterization of four patients carrying partial lossof-function mutations in the steroidogenic acute regulatory protein (StAR). Journal of Clinical Endocrinology and Metabolism 201095 3352-3359. (doi:10.1210/jc.2010-0437)

14 Nakae J, Tajima T, Sugawara T, Arakane F, Hanaki K, Hotsubo T, Igarashi N, Igarashi Y, Ishii T, Koda N, Kondo T, Kohno H, Nakagawa Y, Tachibana K, Takeshima Y, Tsubouchi K, Strauss JF \& Fujieda K. Analysis of the steroidogenic acute regulatory protein (StAR) gene in Japanese patients with congenital lipoid adrenal hyperplasia. Human Molecular Genetics 19976 571-576. (doi:10.1093/hmg/6.4.571)

15 Strushkevich N, MacKenzie F, Cherkesova T, Grabovec I, Usanov S \& Park H-W. Structural basis for pregnenolone biosynthesis by the mitochondrial monooxygenase system. PNAS $2011 \mathbf{1 0 8}$ 10139-10143. (doi:10.1073/pnas.1019441108)

16 Tuckey RC. Progesterone synthesis by the human placenta. Placenta 200526 273-281. (doi:10.1016/j.placenta.2004.06.012)

17 Simard J, Ricketts M-L, Gingras S, Soucy P, Feltus FA \& Melner MH. Molecular biology of the $3 \beta$-hydroxysteroid dehydrogenase $/ \delta 5-\delta 4$ isomerase gene family. Endocrine Reviews $2005 \mathbf{2 6} 525-582$. (doi:10.1210/er.2002-0050)

Received 22 May 2012

Revised version received 4 August 2012

Accepted 11 September 2012 